\title{
THERMODYNAMIC DESIGN OF A SOLAR REFRIGERATOR TO PRESERVE SEA PRODUCTS
}

\author{
Hector D. Arias-Varela, Wilfredo Soto-Gomez and Oscar Castillo-Lopez \\ Metal-mechanical Department, Institute of Technology of Tijuana, Calzada del Tecnologico s/n, Tijuana, Baja California., \\ Mexico 22370, Phone/Fax (66) 833519, E-mail: harias@tectijuana.mx
}

\section{Roberto Best-Brown}

Centro de Investigacion en Energia, Universidad Nacional Autonoma de Mexico, Apartado Postal No. 34, Temixco, Morelos, Mexico 62580, E-mail: rbb@mazatl.cie.unam.mx

\begin{abstract}
This project was developed to determine a means of providing refrigeration to communities lacking conventional energy sources. The design of an absorption refrigeration system operating with solar energy was carried out. The refrigerator is used to conserve sea food. The system is adapted to an industrial size cold-storage room. A maximum of 200 $\mathrm{kg}$ of fish in ice may be introduced to this room daily, up to a total capacity of 2 tons. The lowest temperature the evaporator reaches is $-10 \mathrm{C}$, the high and low system pressures are $13.4 \mathrm{~atm}$ and $2.87 \mathrm{~atm}$ respectively. The refrigerant-absorbent mixture is ammonia and water, where the refrigerant is ammonia. The design of this system requires six effective solar hours to generate the refrigerant needed by the refrigerator to work eighteen hours daily. Evacuated tube solar collectors are used. Only solar energy is used to operate the system. To compare the cost effectiveness of this solar refrigerator with a vapor compressor refrigerator of the same capacity, the following was considered: the vapor compression refrigerator requires electricity generated by internal combustion plant. The period of comparison is twenty five years with a MARR of $4.5 \%$. Initially, solar energy refrigeration is more monetarily expensive, but less expensive ecologically than conventional refrigeration. However, at twenty three years of operation they become the same monetarily. Beyond twenty three years, conventional refrigeration is more expensive.
\end{abstract}

\section{INTRODUCTION}

Most conventional refrigeration systems operate with electricity, however, there are regions where it is difficult or not cost efficient to provide electric service. In addition, the cost of generating electricity is high, both economically and ecologically. Therefore, a project was developed to determine a means of providing refrigeration to communities lacking conventional energy sources. The design of an absorption refrigeration system operating with solar energy was carried out. The refrigerator is used to conserve sea food. Solar refrigeration by absorption is considered to be an alternative to substitute conventional refrigeration equipment and a way to save electricity or make refrigeration possible in areas without electricity.

While research on solar cooling has been carried, a design that operates efficiently and is economically within reach of its users has not been mass produced. The majority of research on solar cooling has focused on lithium bromide and water where water is the refrigerant. This limits the operation of the system to temperatures at or above $5 \mathrm{C}$. Moreover, even the systems designed for high temperature have low efficiency and little competitiveness in the market (Hacuz, 1982).

A list of different experimental prototypes related with solar refrigeration around the world are listed as follows:

- University of Ohita Building, cooling space $1860 \mathrm{~m}^{3}$, flat plate collectors copper/copper, collection area $513 \mathrm{~m}^{2}$, and a refrigeration unit working by absorption with lithium-bromidewater with a capacity of 30 tons (Japan).

- Solar House Hirakata, cooling space $118.5 \mathrm{~m}^{3}$, evacuated tube collectors copper-aluminum, area of collection $46.6 \mathrm{~m}^{2}$, and a refrigeration unit working by absorption with lithium-bromidewater with a capacity of 2 tons (Japan).
- Santa Clara Ca. Recreation Center, cooling space $2508 \mathrm{~m}^{3}$, flat plate collectors copper/copper, collection area $650 \mathrm{~m}^{2}$, and a refrigeration unit working by absorption with lithium-bromidewater with a capacity of 25 tons (USA).

- Brisbane Solar House, cooling space $123 \mathrm{~m}^{3}$, flat plate collectors copper/copper, collection area $6 \mathrm{~m}^{2}$, and a refrigeration unit working by absorption with lithium-bromide-water with a capacity of 2 tons (Australia).

- Carrier Corporation Phoenix Arizona, cooling space $3700 \mathrm{~m}^{3}$, linear lenses, collection area $133.8 \mathrm{~m}^{2}$, and a refrigeration unit working by absorption with lithium-bromide-water with a capacity of 13.5 tons (USA) (Huacuz 1992), (Bogart, 1992) (Mongomery, 1991) and (Instituto de Refrigeracion y Aire Acondicionado, 1989).

This paper concentrates on the thermodynamic design and analysis of a solar refrigeration system. The project is unique since the system is adapted to an industrial size cold-storage room and developed to operate under the following conditions: temperatures less than $0 \mathrm{C}$ in the evaporator, 18 hours of operation per day, storage of refrigerant, approximately 6 effective solar hours of solar collection with evacuated tubes and the use of solar energy as the only source of power to operate the system.

The components of the solar refrigerator are shown in Figure 1. The elements of the system located in the high pressure region are the following:

- Evacuated Tube Solar Collectors. The function of this component is to heat the thermal oil used by the generator. 
- Generator. This element is a heat exchanger whose main purpose is to heat the ammonia-water mixture in order to separate the water from the ammonia.

- Separator. This is a more sophisticated heat exchanger that ensures approximately one hundred percent of ammonia separation from water.

- Condenser. This heat exchanger uses water in order to condense the ammonia that will be used as the refrigerant. After the refrigerant is condensed it is sent to the refrigerant tank.

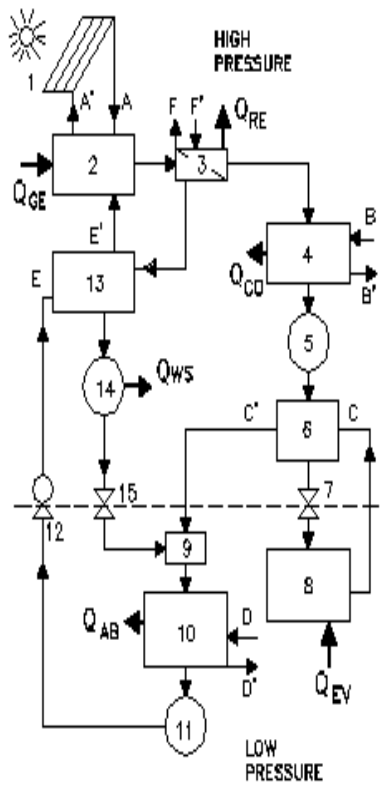

\begin{tabular}{|c|}
\hline 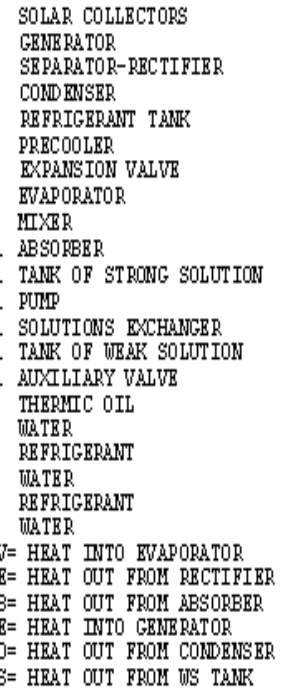 \\
\hline
\end{tabular}

Figure 1. Components of the solar refrigerator.

- Refrigerant Tank. This tank keeps the refrigerant that is released as required. After this tank, there is a pre-cooler that causes the temperature of the ammonia (at liquid state) increase.

- Pre-cooler. This heat exchanger uses the ammonia that returns from the evaporator at high temperature in order to elevate the temperature of the refrigerant that comes from the refrigerant tank and passes to the expansion valve.

- Expansion Valve. This valve regulates the refrigerant flow and lowers the pressure of the system before the ammonia enters the evaporator.

- Evaporator. Through this element, the refrigerant that absorbs the surrounding heat circulates so that the space around the evaporator becomes colder.

The components of the system located in the low pressure region are the following:

- Mixer. This component mixes the ammonia that comes from the Pre-Cooler with the water that has been separated from the ammonia in the high pressure region. Then, the mixture is absorbed by the Absorber.
- Absorber. This element contains enough water to absorb the mixture of water-ammonia or ammonia that comes from the mixer. After the absorption takes place, the solution with a high concentration of ammonia is send to the tank of strong solution.

- Tank of Strong Solution. This tank keeps the ammonia-water solution. This solution is released as required and pumped to the high pressure region.

- Pump. This component pumps the solution to the generator w (in the high pressure region). The pump is powered by electricity which is generated with photo-voltaic panels.

\section{THERMODYNAMIC ANALYSIS OF THE SYSTEM}

A thermodynamic analysis of the system was carried out quantitatively. Calculations were made to determine the minimum characteristics of the system that are needed to guarantee its operation.

First, the balance of energy was calculated. The dimensions and characteristics of the refrigerator are shown in Figure 2. The walls are constructed of brick and concrete and the interior lined styrofoam sheets for insulation. The thickness of the insulation is $10 \mathrm{~cm}$. The roof consists of a concrete with gravel with a thickness of $10 \mathrm{~cm}$ and styrofoam insulation of the same thickness. The construction of the floor is similar to the roof. The difference is that the insulation is placed between the concrete floor and the ground. The height of the refrigerator is $2.3 \mathrm{~m}$. An interior temperature of $1 \mathrm{C}$ must be maintained. The exterior atmospheric temperature is considered to be $40 \mathrm{C}$, which is the average high temperature in the region. The total heat flow for the building was calculated to be $1.5 \mathrm{kw}$.

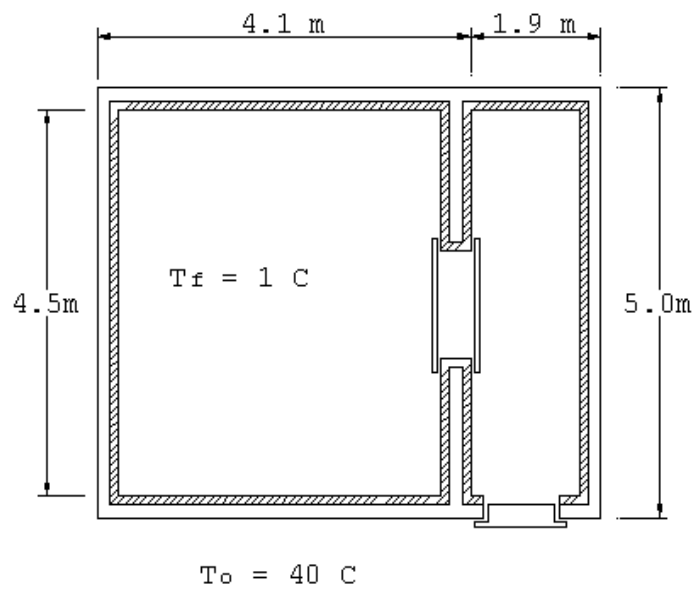

Figure 2. Dimensions of storage room.

Next, the refrigeration load was calculated. The system=s total refrigeration load originates from the following sources of heat: heat transmission between the difference in interior and exterior temperatures, load of the products which are introduced at room temperature and that must be cooled to the temperature of the refrigerator, air infiltration, supplementary loads caused by electric lights, motors, tools, and even people. The energy needed to reduce the temperature of the fish from $35 \mathrm{C}$ to $1 \mathrm{C}$ was calculated based on the conservation of $200 \mathrm{~kg}$ of fish per day. The product load was found to be equal to $6.9 \mathrm{~kW}-\mathrm{h}$. The load caused by air infiltration was considered to be within the range of 
design safety factor along with the supplementary load since the volume of the refrigerator is relatively small and the number of times the doors will be opened is minimal. In addition, the refrigerator does not have much supplementary equipment. The total load of the refrigerator was found to be $2.0 \mathrm{~kW}$.

The following characteristics were also calculated:

1) Total mass of ammonia, $100 \mathrm{~kg}$

2) Concentration of ammonia and water, 0.42

3) Condensation pressure at $34 \mathrm{C}, 12.94 \mathrm{~atm}$

4) Total mass of the solution, $961.29 \mathrm{~kg}$

5) Energy required by the generator, $14.02 \mathrm{~kW}$

6) Rectification energy, $4.927 \mathrm{~kW}$

7) Condensation energy, $5.37 \mathrm{~kW}$

8) Absorption energy, $2.5867 \mathrm{~kW}$

9) Energy transferred by the weak solution, $2.00 \mathrm{~kW}$

10) Work by the pump, $0.0523 \mathrm{~kW}$

The thermodynamic properties of the system are indicated and explained in Figure 3. Based on the energy balance, the system is considered to respect the First Law of Thermodynamics. The energy types entering the system, inputs, are the heat of generation (QGE), the heat of evaporation (QEV) and the work of the pump (WвO). The energy types going out the system, outputs, are the heat of condensation (QCO), the heat of rectification (QRE), the heat of absorption (QAB), and the heat transfered by the weak solution while in the weak solution tank (Qws). The energy balance results are shown in Table 1 where it is observed that input of energy, $120.43 \mathrm{KW}-\mathrm{H}$, is almost the same as the output, $120.36 \mathrm{KW}-\mathrm{H}$.

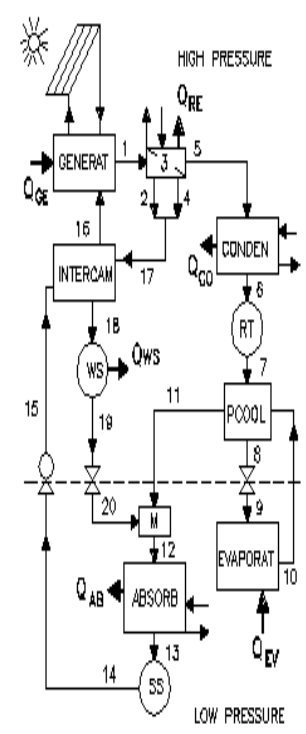

\begin{tabular}{|c|c|c|c|c|c|}
\hline No. & Pressure & Temper. & Concen- & Mass. Flow & Op. Time \\
\hline & stm & $C$ & tration & kgh & $h$ \\
\hline 1 & 12.94 & 105 & 0.420 & 160.21 & 6 \\
\hline 2 & 12.94 & 105 & 0.326 & 134.85 & 6 \\
\hline 3 & 12.94 & 105 & 0.920 & 25.35 & 6 \\
\hline 4 & 12.94 & 43.5 & 0.768 & 8.67 & 6 \\
\hline 5 & 12.94 & 43.5 & 0.999 & 16.68 & 6 \\
\hline 6 & 12.94 & 34 & 0.999 & 16.68 & 6 \\
\hline 7 & 12.94 & 34 & 0.999 & 5.56 & 18 \\
\hline 8 & 12.94 & 25.96 & 0.999 & 5.56 & 18 \\
\hline 9 & 2.87 & -10 & 0.999 & 5.56 & 18 \\
\hline 10 & 2.87 & -10 & 0.999 & 5.56 & 18 \\
\hline 11 & 2.87 & 7.9 & 0.999 & 5.56 & 18 \\
\hline 12 & 2.87 & 37.8 & 0.420 & 53.40 & 18 \\
\hline 13 & 2.87 & 34 & 0.420 & 53.40 & 18 \\
\hline 14 & 2.87 & 34 & 0.420 & 160.21 & 6 \\
\hline 15 & 13.14 & 34 & 0.420 & 160.21 & 6 \\
\hline 16 & 13.14 & 88 & 0.420 & 160.21 & 6 \\
\hline 17 & 12.94 & 102.5 & 0.352 & 143.52 & 6 \\
\hline 18 & 12.94 & 48.2 & 0.352 & 143.52 & 6 \\
\hline 19 & 12.94 & 34 & 0.352 & 47.84 & 18 \\
\hline 20 & 2.87 & 34 & 0.352 & 47.84 & 18 \\
\hline & & & & & \\
\hline
\end{tabular}

Figure 3. Results of thermodynamic analysis.

\section{THERMIC AND MECHANICAL ANALYSIS}

This section examines the thermic and mechanical characteristics of the elements of the system. For the selection of these elements, existing commercial equipments is considered first. For elements that are not available commercially, design calculations necessary for the fabrication of these parts were carried out.

Table 1. Energy Balance Results.

\begin{tabular}{|c|c|c|c|c|}
\hline \multicolumn{2}{|c|}{ Enrgy } & Op. Time & Energy In & Energy Out \\
\hline Type & KW & $h$ & KN-h & KW-h \\
\hline QGE & 14.02 & 6 & 84.12 & --- \\
\hline QEV & 2.00 & 18 & 36.00 & --- \\
\hline WEO & 0.05 & 6 & 0.31 & --- \\
\hline QCO & 5.37 & 6 & --- & 32.22 \\
\hline QRE & 4.92 & 6 & --- & 29.52 \\
\hline QAB & 2.59 & 18 & --- & 46.62 \\
\hline QSD & 2.00 & 6 & --- & 12.00 \\
\hline Total & & & 120.43 & 120.36 \\
\hline
\end{tabular}

For the thermic and mechanical analysis, the main components of the system are the following: Solar Collectors, Generator, Separator-Rectifier, Condenser, Condensation Tank, Cooler, Evaporator, Absorber, Strong solution tank, Mixer, and Weak Solution Tank. The other components of the system are considered to be complementary equipment.

The Solar Collectors. After analyzing the efficiency and cost of evacuated tube solar collectors manufactured by various companies the decision was made to use Suntube which is designed to provide optimal efficiency for the collection of solar energy at a minimum cost (Nipon Electric Glass, 1990). It allows a $30 \%$ reduction in the required collection area. In addition it has a long service life due to its closed construction which effectively prevents problems such as corrosion and leaks. The solar collector tube may be installed horizontally which not only permits the use of virtually any part of the surface, but also assures that the collector can be integrated into the existing building. Due to its especial layer it has a high rate of absorption ( 0.91 minimum) and a low rate of emissions ( 0.12 maximum). Figure 4 show a diagram with which the efficiency can be determined as a function of irradiation, air temperature, and the average operating temperature of the fluid.

The area of the solar collectors required by the system was determined based on the quantity of energy demanded and the mass flow of required heat exchange fluid. The energy demand of the generator is $16 \mathrm{KW}$ ( considering a safety factor of $15 \%$ ). The quantity of heat exchange fluid required can be calculated based on the proposed entrance and exit temperatures of the oil in the generator. The oil used is Marlotherml. The average specific heat is calculated to be $0.825 \mathrm{kcal} / \mathrm{kg} \mathrm{C}$. For $16 \mathrm{KW}$, a result of $1667.87 \mathrm{~kg} / \mathrm{h}$ is obtained. Since the average density of Marlotherml $(110-120 \mathrm{C})$ is $912 \mathrm{~kg} / \mathrm{m}^{2}$, the volume required is calculated to be $1819.5 \mathrm{l} / \mathrm{h}$. 


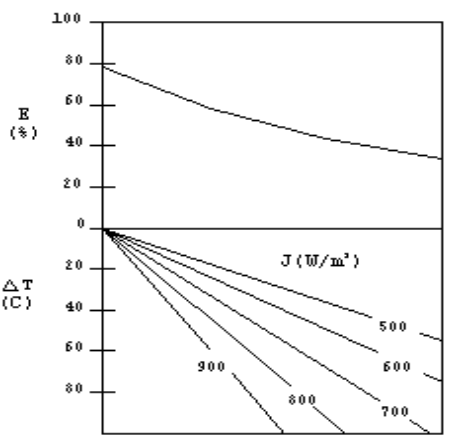

Figure 4. Solar collectors efficiency.

To determine the efficiency of the solar collectors using Figure 4 , it is necessary to know the temperature difference and the solar radiation. The temperature difference was calculated to be $83 \mathrm{C}$. The average solar radiation in $\mathrm{W} / \mathrm{m}^{2}$ for the region studied was obtained from a manual of the Institute of Engineering of the UNAM ACalculo de la Radiation Solar Instantanea en la Republica Mexicana.@ (Fernandez, 1990). For an average of six hours of effective solar radiation, the value of $597.7 \mathrm{kcal} / \mathrm{m}^{2} \mathrm{~h}$. In this case the efficiency of the solar collectors is $\mathrm{E}=0.4$. The energy absorbed is $278 \mathrm{~W} / \mathrm{m}^{2}$. This result in a total absorption area of $57.55 \mathrm{~m}^{2}$ to satisfy the demand of $16 \mathrm{KW}$, or 32 collectors arranged in four rows of eight.

The use of oil in the solar collectors causes a drop in pressure which was calculated to be $67.87 \mathrm{lb} / \mathrm{pig}^{2}$ This drop in pressure requires a $3 / 4 \mathrm{hp}$ motor.

The Generator. A high pressure generator with carbon harden steel tubes and fins was selected because of the use of a solution containing ammonia.

The Separator-Rectifier. Due to the difficulty of finding a separator-rectifier that is able to cool the vapor to allow all of the water to condense and produce a vapor that is pure ammonia, the decision was made to design it and order its construction by an industrial shop. The separator consists of a distillation column of carbon hardened steel. The nucleus of the column has a series of washers the facilitate the separation of the vapor.

The Condenser. A heat exchanger of armor plating and tubes was chosen since a heat exchanger of double tubes required a length of nearly 30 meters.

The Refrigerant Tank. The condensation storage tank must be able to store 1701 of ammonia along with a addition $15 \%$ of the gases that are not able to be condensed or 25.51 .

The Precooler. The precooler of the liquid refrigerant uses $1.53 \mathrm{~m}$ long coiled tubing with a diameter of $5.5 \mathrm{~mm}$ in a carbon hardened steel tube 0.5 meters long with a diameter of $6.5 \mathrm{~cm}$.

The Evaporator. An evaporator with the following characteristics was chosen:

Finned tubing: Fins welded with high frequency resistance in a helicoidal form

Exterior diameter $(\mathrm{cm}): \quad 3.34$

Wall thickness $(\mathrm{cm}): \quad 0.33$

Length with fins (m): $\quad 4.89$
Length without fins (cm): $\quad 10.16$

Total length (m): $\quad 4.99$

Fins per inch $(2.54 \mathrm{~cm}): \quad 5$

Height of fins (cm): $\quad 1.90$

Type of fins: $\quad$ Solid HF

Tube material: Carbon hardened steel

Number of Tubes: $\quad 3$

The absorber. The strong solution storage tank must guarantee the storage of 1,137.5 1 of a solution of ammonia and water at a pressure of $3 \mathrm{~atm}$ and a temperature of $34 \mathrm{C}$ in addition to $10 \%$ of the non condensable gases (113.75 1) for a total of 1,252.25 1 . It is a carbon hardened horizontal cylinder $1.22 \mathrm{mts}$ long.

The mixer. A maximum of $200 \mathrm{~kg}$ of fish in ice may be introduced to this room daily, up to a total capacity of 2 tons. The lowest temperature the evaporator reaches is $-10 \mathrm{C}$, the high and low system pressures are 13.4 atm and 2.87 atm respectively. The refrigerant-absorbent mixture is ammonia and water, where the refrigerant is ammonia. The design of this system requires six effective solar hours to generate the refrigerant needed by the refrigerator to work eighteen hours daily. Evacuated tube solar collectors are used.

A photovoltaic system is also required to power the principle electrical components, the motors of the hydraulic system, each with a different capacity. The equipment is as followed: a pump for oil, 3/4 h.p., $750 \mathrm{~W}$, operating 6 hours per day; a high capacity pump for water, $500 \mathrm{~W}$, operating 6 hours pers day; a pump for $\mathrm{NH}_{3}-\mathrm{H}_{2} \mathrm{O}, 1 / 4$ h.p., $250 \mathrm{~W}$, operating 6 hours per day; and a low capacity pump for water, 1/8 h.p., $125 \mathrm{~W}$, operating 12 hours per day. The total amount of energy required is the sum of the potentials multiplied by the operating hours, $10,500 \mathrm{~W}$. To determine the energy total that must be provided, it is also necessary to consider the energy that the components of the photovoltaic system consume. This self-consumption energy can be calculated with the energy efficiency of the elements of the system. The values are as follows: current invertor $95 \%$, charge controller $95 \%$, lead acid batteries $90 \%$. The total energy that must be furnished by the photovoltaic system is $12,927.054 \mathrm{~W}$. The peak potential, in $\mathrm{KWp}$, is proportional to the average total energy required per day, over the average solar radiation per day, expressing the solar radiation in $\mathrm{KWh} /$ day. Therefore, the peak potential is 2,5854 $\mathrm{KWp}$. The selected electric equipment works within the range of 115-125 volts. For calculations a nominal voltage of 125 volts is used. Therefore, the current demanded by the system is 20.68 amp. The proposed batteries are lead acid 12.5 volts DC, the recommended charging voltage is 14.5 volts. In addition, if the nominal voltage required is 125 volts, it is necessary to connect in a series 10 batteries of 12.5 volts. moreover, to charge 10 batteries in a series 145 volts are required. If the batteries are 12.5 volts/200 amp-h and if a battery bank with 3- day autonomy is desired, the bank has to be three parallel lines with a series of 10 batteries in each line. The proposed battery is made by SIEMEN with a potential of $53 \mathrm{~W}, 17$ volts and 3 amps. The photovoltaic arrangement needed to provide 145 volts and 20.68 amps consists of seven parallel line with nine modules in a series in each one of them. Overall, 63 modules are necessary to supply the required energy.

\section{COST ANALYSIS}

In this section a cost analysis which compares the solar absorption refrigerator designed for this project for which the 
only source of energy is solar with a conventional vapor compression refrigerator which uses a gasoline-powered electric generator was carried out. To compare the cost effectiveness of this solar refrigerator with a vapor compressor refrigerator of the same capacity, the following was considered: the vapor compression refrigerator requires electricity generated by internal combustion plant. This uses fuel whose price increases at an annual inflation index of $9.1 \%$ (average in Mexico for the last 10 years). The period of comparison is twenty five years with a minimal attractive rate of return (MARR) of $4.5 \%$ per year. All monetary values are stated in U.S. dollars since it is a more stable currency.

The approximate cost of the solar refrigeration system was obtained using the prices of the components of the system: 32 solar collection modules, $\$ 17,280.00$; oil pump, $\$ 540.00$; generator $\$ 3,270.00$; separator-rectifier, $\$ 1,166.67$; condenser, $\$ 1,855.26$; condensation storage tank, $\$ 933.63$; pre-cooler, $\$ 318.34$; evaporator $\$ 2,112.18$; absorber, $\$ 1,985.53$; strong solution storage, $\$ 2,235.60$; mixer $\$ 2,485.00$; weak solution storage \$2,005.60; expansion valve (refrigerant), \$135; expansion valve (weak solution), $\$ 65.00$; pump (solution) $\$ 375$; high capacity pump (water), $\$ 440.00$, low capacity pump (water), $\$ 214.00$; cooling tower, $\$ 2,471.73$; photovoltaic system, $\$ 55,113.34$. The total cost is $\$ 95,001.88$ U.S. Dollars. The cost of the equipment necessary for the connections is not included, neither is the cost of the fluids. The price of the equipment does not include installation. The cost of the solar energy is $\$ 0.00$ dollars.

The cost of a conventional system with the same characteristics as the solar refrigeration system is $\$ 7,991.44$ U.S. dollars. However, the replacement of equipment has to be considered. The gasoline powered generator which its cost is $\$ 960.00$ has to be replaced every five years. The compressor unit and other components which their costs add up to $\$ 4,000.00$ have to be replaced every 10 years. The cost of the gasoline required to operate the generator must also be calculated. It is estimated that it will consume 1.5 liters per hour of operation and run 9 hours a day for 25 years.

Initially, solar energy refrigeration is more monetarily expensive, but less expensive ecologically than conventional refrigeration. However, at 23 years of operation they become the same monetarily. Beyond 23 years, conventional refrigeration is more expensive as shown in Figure 5.

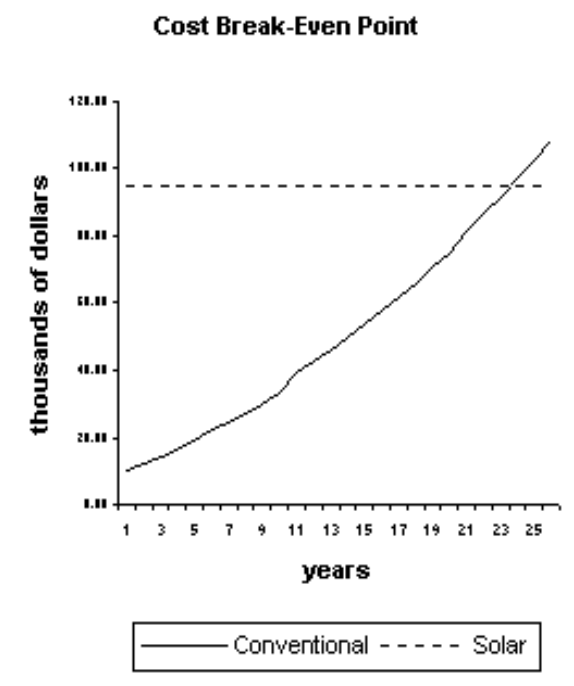

Figure 5. Costs of the conventional and solar refrigerators.

\section{CONCLUSIONS}

The construction of a solar refrigerator to conserve sea products is technologically feasible and it can be an alternative to provide refrigeration to rural communities which do not have electric service. Although the initial cost of the solar refrigerator is relatively high and it makes this alternative less attractive economically, it could be an acceptable solution since the cost of the conventional and solar refrigerators become the same at approximately 23 years of operation with a MARR of $4.5 \%$. In addition, the costs of the solar refrigerator can be reduced significantly if this equipment is mass produced. Many of its components can be improved and standardized in the future which will lower the costs of the solar refrigerator.

\section{REFERENCES}

Bogart Marcel (1992) Ammonia Absorption Refrigeration in Industrial processes, 1st edn, pp. 5-15. GULF, New York.

Fernandez Zayas Jose (1990) ACalculo de la Radiacion Solar Instantanea en la Republica Mexicana@ Instituto de Ingenieria UNAM Serie No. 472

Huacuz Jorge (1992) AEstudios de Refrigeracion Solar@ Boletin del Instituto de Investigaciones Electricas, Vol. 6 Issue No. 2. Instituto de Refrigeracion de Aire Acondicionado (1989) Manual de Refrigeracion y aire Acondicionado, 2nd edn, pp. 213-218. Prentice Hall, Mexico D.F.

Montgomery Richard (1991) Energia Solar. Seleccion del Equipo, Instalacion y Aprobechamiento, 1st edn, pp.86-90. LIMUSA, Mexico D.F.

Nipon Electric Glass (1990) ATechnical Data for NEG Evacuated Tube Solar Collector and Solar Collector Module LD-2800/DP62800@ Nipon Electric Glass Co., Ltd. 